\title{
XXIst CENTURY INTERIOR DESIGN
}

\begin{abstract}
Today's approaches to the design of modern interiors have changed significantly. This is due to such reasons and conditions as: socio-economic terms of interiors' use and service, rapid technical progress, the development of science and information technology, growing environmental requirements in accordance with the principles of sustainable development, the introduction of new building materials and technologies, accounting accessibility and national traditions, human-centered design, etc.

The purpose of the article is identification of conditions, features, principles and guidelines for the design of modern interiors. The study is based on a systematic approach that defines hierarchical levels of interior design. Methods of historical and comparative analysis were also used.

The article discusses the factors and conditions of modern interiors' formation, features and principles of their functional and spatial solutions. The hierarchical levels and methodological provisions of the architectural environment design of modern interior spaces are revealed.
\end{abstract}

Keywords: interior design, modern conditions, civil buildings, system-structural principles, hierarchical levels

\section{Introduction.}

In the last two decades, the issue of interior design, when taking into the account significant changes in the circumstances of its use, has taken one of the central places in architectural academic discussions. This is due to the fact that approaches to shaping the design of the modern interiors of buildings have changed significantly. The reasons for this are as follows: processes of globalisation and influences of socio-cultural identity; the development of science, technology, information and construction technologies; increasingly stricter requirements concerning environmental friendliness, aesthetic expressiveness and creating a barrier-free environment; compliance of the newly created interiors with the principles of sustainable development; requirements for a human-centered approach to design, etc.

When developing new approaches in the design of modern interiors, there is a need to perform work in parallel with continuous analysis of the obtained results and adjustment of the previous steps to meet the diverse human needs of the present day. The application of human factors and ergonomics to interactive systems design enhances effectiveness and efficiency, improves human working conditions, and counteracts possible adverse effects of use on human health, safety and performance. Applying ergonomics to the design of systems involves accounting for human capabilities, skills, limitations and needs. Human-centred systems support users and motivate them to learn. But the constant, rapid development of information technologies has a direct impact on the diversification of building interiors and on their changes coming in conjunction with the complication of the internal functional organisation (ISO 13407, 1999, 4p.).

In general, contemporary interior design should be characterised by: multifunctionality, openness, communi- cativity and a barrier-free approach to all socio-demographic groups; the combination of internal and external architectural environment qualities; aesthetic integrity and uniqueness of the visual image, which will help visitors to think and focus on the focal point of the composition of the space; informative saturation, etc.

The basis for the formation of the methodological base of the study were fundamental scientific and practical works on the design of the interior environment of buildings, developed by architects-researchers: Le Corbusier, Mies van der Rohe, Frank Lloyd Wright, Alvar Aalto, Kenzo Tange, Eliel Saarinen, Oscar Niemeyer, Frank Gehry, Renzo Piano, Norman Foster, Rem Koolhaas, Herzog \& de Meuron, Hans Hollein, Daniel Libeskind, Jean Nouvel, Karim Rashid, Zaha Hadid, Philippe Starck, Naoto Fukasawa, and Tadao Ando, as well as others whose names are not so widely known (Cohen JL, 2004, pp. 25 - 30; Sloan Julie L, 2001, pp. 210 216; Krohn C, 2019, pp. 93 - 108).

Problems of the architecture of certain types of public buildings and their interiors are considered in the works of modern Ukrainian architects and designers: V. Abyzov, I. Kuznetsova, O. Oliynyk and others. Issues of the design of intelligently managed living environments are explored by O.Polyakova (Abyzov V, 2017, https://iopscience. iop.org/article/10.1088/1757-899X/471/8/082004/ meta (13.07.2020); Poliakova O, 2018, 91 - 102pp.). At the same time, a there is no crystallised holistic approach to the design of contemporary interior spaces of buildings in recent years, and the literature on this subject is scant. There is a need to develop a comprehensive vision for the formation of the interior design of buildings and complexes at the present

* Prof., Dr.Sc/Hab. Ing.-Arch., Kyiv National University of Technology and Design, Ukraine, e-mail: vaddimm77@gmail.com, ORCID: 0000-0002-5494-8230.

** Ph.D., Ing.-Arch., Kyiv National University of Technology and Design, Ukraine, e-mail: kysil.ss@knutd.edu.ua, ORCID: 0000-00021973-6152. 
stage, taking into account the latest socio-economic and technological changes around the world.

The purpose of this article is to identify the conditions, features, principles and guidelines for the design of modern interiors.

Research Methods. The study is based on a systematic approach that helps to determine the hierarchy of system-structural foundations for the design of contemporary interiors. The systematic approach also made it possible to establish links between the technical constituent of modern interior spaces design, their functionality and aesthetic expressiveness, to distinguish the design approaches to the formation of modern interior spaces.

Both general (theoretical and empirical) and specialist methods of academic research (historical, comparative, typological and artistically-compositional) are applied in the work. The complex of these methods contributed to the analysis of the design of the modern interior environment of buildings and structures through the prism of historical, artistic, scientific and technical features and factors.

\section{The key factors and conditions that determine the for- mation of modern interior design}

Designing a modern interior is a complex creative process, which takes into account many key factors that affect the functional, spatial, compositional, artistic and aesthetic decisions, and the comfort of use of modern interiors. They can be divided into external and internal factors of influence. External factors influence the formation of the architectural environment as a whole and relate to the conditions of the pre-design analysis. These are: socio-economic, natural-climatic, urban planning, environmental, material and technical factors. In turn, the group of internal factors that directly affect the formation of interior design, include the following subgroups: typological, ergonomical, psycho-emotional, technological, and cultural.

Socio-economic factors affect human needs and values as a matter of priority. In interior design, this is reflected in customer revenue levels. Depending on the level of income (low, medium or high), the owners will, for example, divide the types of residential interiors into categories and implement their respective architectural and technological solutions that will be reflected in the interior design.

At the same time, a human-centered approach to interior design is being developed. This design strategy involves the direct involvement of customers in the development of interior designs and allows for integrating specific human needs and technological capabilities to meet design objectives (ISO 13407, 1999, pp. 5 - 6).

Natural climatic factors include climatic and geological conditions of construction and determine the relationship with the environment. They determine: the orientation of the building in cardinal directions, insolation, aeration, the effects of temperature and noise modes, humidity, the implementation of engineering systems of life support, general constructive and spatial structure (Rozhdestvenskaia ES, 2007, pp. 132 - 138).

Urban planning factors, closely related to the climatic conditions, determine the location of the building within an urban environment and influence the formation of the spatial composition of the interior, taking into the account characteristics of the construction sites and the environment.

Environmental factors are also closely related to natural climatic conditions and take into account: sanitary and hygienic parameters (required temperature and humidity; sound, visual comfort and insolation), and microclimatic conditions of the environment of human life. In turn, complying with the requirements of beauty, comfort, economy, the consumption of resources, origin of materials, the safety of use of products, simplicity and safety of their processing with the possibility of re-use with minimal environmental harm are also of key significance. It is necessary to adhere to an environmental approach, the so-called " $3 \mathrm{R}^{\text {"- - }}$ "reduce, reuse, recycle"-reduction, reuse and recycling (Smoliar YM, Mykulyna EM, Blahovydova NH, 2010, pp. 54 57.; Voskresenskyi Y N, 2004, pp. 66 -74).

In order to take into account environmental factors, it is necessary to incorporate eco-friendly, durable finishing materials-natural stone, ceramic tile, wood, veneer, etc. into the interior designs. The modern aspect of this factor is the application of possible measures for the protection of the environment, by introducing elements of recycling, upcycling, downcycling, etc into the interior.

Material and technical factors include: the level of development of structural systems, their technical solutions and modern methods of buildings construction, as well as the latest construction and finishing materials. This factor affects the variability of interiors and their furnishings., Artists find unusual solutions for use in furniture design, including shapes, colours, textures, etc., the latest materials and decorative elements such as carbon fibre, synthetic resins, methacryl, plexiglass, flexible stone, smart glass, liquid or live interactive coatings, nanomaterials etc. (Abyzov V A, 2009, pp. 53 -54). Typological factors determine the basic functional, technological and structural image of the building-composition, parameters of premises, the formation of their functional and planning organisation.

At the same time, the service structure is being transformed and existing types of buildings are being modified accordingly as new ones are being developed with improved functional planning. Diversity is increasing and related functions are expanding, both in residential and public interiors, which requires the use of state-of-the-art equipment and technologies in interiors.

Ergonomic factors affect the following: complex spatial and compositional interior design, functional and spatial parameters that are properly selected, structural parameters of the interior according to the anatomical features of the human body, determination of the object-space environment design.

Psycho-emotional factors determine the psychological and emotional perception of a harmonious en- 
vironment, scale, proportions, colour climate, lighting, landscaping, the use of works of art that characterise changes in the health oh humans and their physical and mental condition.

Technological factors determine the formation of the general structure of the interiors, as well as the creation of their corresponding thematic content, considering the latest technological advances. Interactive objects become valuable components in the organisation of the domain space.

Cultural factors reflect socio-cultural identification, take into the account historical and cultural traditions, and affect the creation of various artistically motivated interior decisions and design elements in particular. Along with multivariate design solutions, it is important to ensure the integrity of the composition and the imaginative personality of modern interiors.

Based on the above, it can be stated that above-mentioned external and internal factors and their changes are distinguished by dynamic development over the time, as well as by uneven influence on the design solutions of modern interiors.

At the same time, over the past thirty years, new factors have emerged that determine the design of contemporary interiors. These include: lack of segregation when visiting a particular interior space; a barrier-free, person-centered approach focused on the usability of the space based on the underlying human behaviour. As a result, the former role of the twenty-first-century designer has now shifted from the limited task of a "form-giver" to a broader scope of tasks, which covers public communications, strategies and human interactions (Alkhalidi AS, 2014, pp.11 - 21; Brown T, Wyatt J, Winter 2010, pp.3335; Buchanan R, 1992, pp.27 - 32).

\section{Modern features and principles of interior design for- mation}

An analysis of the factors influencing the design of contemporary interiors allowed us to formulate the principles of their design, which include: socio-economic relevance, expediency, multivariability, dynamism and aesthetic harmonisation. However, such a system of principles for the formation of interior design cannot be uniquely defined and exist in the form of an axiom. Specific objects and design tasks play a decisive role here. However, in the practice of design, a number of core principles have been established for creating such a system product, i. e. interior design and its object-space content. These principles can and should be modified, developed and supplemented by new ones.

The principle of socio-economic relevance is at the heart of differentiating the design of modern interiors, basing on one of three levels of consumers income-low, medium, high. Depending on the level of income and the life needs of the customer, the freedom to choose the necessary interior design is created, e.g. affordable or elite class housing.

The design of an interior must be human-centered, consistent with human-centered approaches, and understandable by the individual. Namely, it must be: modern, affordable, comfortable, barrier-free, multifunctio- nal, transformative and dynamic, etc., and possess such attributes as-physicality, intellectuality, sociability, emotionality, personability, etc.

The principle of expediency determines the well-planned and balanced population of the system with elements of different levels, which must contribute to the end result, and should not be accidental or logically incorrect. Indeed, ensuring that planning corresponds to the functional purpose of a space, satisfying affordability, environmental friendliness and cost-effectiveness in the design of contemporary interiors - those are mandatory requirements, reflecting the principle of expediency when designing the interior environment of buildings.

The principle of multivariance determines the possibility of the universal use of an interior space. For example, in residential and public spaces, this versatility is determined by the application of barrier-free spaces, mobile furniture, divider partitions, screens, etc.

Modern, highly-efficient interiors are a brand new structure that combines many functions and purposes: information and cultural services, education, recreation, sports and entertainment, medicine, trade, transport, and more. They include different types of spaces that are appropriate to their use. In the course of such activities, certain functions may be modified and supplemented depending on the influence of social requirements and market conditions. In these circumstances, it is necessary to ensure the combination of various elements into a coherent structure, the stability and effectiveness of which is based on the interaction of its constituent elements. Creating highly effective innovative interiors requires the integration of various functional elements into a single interconnected organism, that is determined by the principle of multivariance.

The principle of dynamism implies uninterrupted and reliable functioning of modern interiors in terms of innovative efficiency,, which gives the opportunity to respond quickly to changing market demands. The interior must "interact" with its consumers and visitors and adapt under the influence of various factors, have a flexible dynamic structure ready for improvement and change. Flexibility and capacity for transformation determine the dynamism and versatility of contemporary interior solutions. With the need for constant renewal of space and its content, the solutions of modern interiors require the creation of universal spaces and the provision of measures for changing their parameters (including planning, furnishing, equipment, laying communications, etc.).

The principle of aesthetic harmonisation involves the consideration of artistic, imaginative, and stylistic solutions, inplementing attractive visual perception, aesthetically improving and organising the harmonious integrity of modern interiors through the application of the basic laws of composition and compliance with the chosen style. 
Essential to this principle in the design of contemporary interiors is the focus on the construction of a multifunctional, comfortable, accessible and aesthetically pleasing spatial structure, which is also harmoniously connected with the environment.

Adherence to these principles implies the organisation of multifunctional, comfortable, barrier-free, environmentally friendly, aesthetically harmonious, economically balanced interior decisions. Creating a modern interior requires the integration of all functional and spatial elements into a single interconnected organism to ensure sustainability and efficiency, with properly formulated energy efficiency and eco-design strategies.

An example of a modern interior solution that meets certain systemic and structural principles is clearly evident in the interior design of the Beijing Daxing International Airport (Fig. 1). Designed by Zaha Hadid Architects, the new Beijing Daxing International Airport is the largest single-structure airport in the world. With a modern design, the new Beijing airport has the appearance of a starfish from above. Its main goal was to be the biggest transport hub for the area with the world's fastest-growing demand for worldwide travel. Zaha Hadid was inspired by the principles of traditional Chinese architecture that unify spaces around a central courtyard. The radial configuration of the airport's interior ensures the farthest boarding gate can be accessed in a walking time of under eight minutes. The new Chinese airport's dense modern interior design minimises distances between check-in and gates, as well as connections between gates for transporting passengers. The public areas of the building shown in the images feature dark, polished-stone floors and white undulating ceilings that open up at regular intervals to create enormous skylights.
Another interesting example of an interior design solution that implements the principles listed above and in which the space interacts with visitors and adapts under the influence of various factors-and has a flexible dynamic structure ready for development and change-is the space of permanent exposition of the F. Chopin Museum in Warsaw (Fig. 2).

Combining the interior with audio, stereo, video effects and visual installations gives visitors the impression that they are immersed in the history of music. Excerpts from the composer's works are heard on all floors of the museum in different formats.

In the "Music Salon" of the museum, there are circles drawn on the floor, , equipped with sensors. By stepping on them, the visitor can listen to the melody by the composer, performed by various instruments. Multimedia content is correspondingly housed within the interior design of the F. Chopin Museum's permanent display on multifunctional panels, monitors, and "iWall"'-type touch walls (Hughes P, 2010, pp. 144 - 149).

TThe Solidarity Museum in Gdansk, which is dedicated to the history of the Polish "Solidarity" movement (Fig. 3), is the embodiment of the principles of contemporary interior design as well. The space of the center is an example of a modern museum that engages in dialogue with visitors. The interior of the museum includes: exhibition halls, offices, a spacious central courtyard that cuts the building in half. The interior of the center is decorated in an industrial style. The exhibition halls are filled with historical exhibits, original documents and newsreels, as well as large-format spatial installations

III. 1. Beijing Daxing International Airport (arch. "Zaha Hadid Architects», Daxing, Beijing \& Guangyang, Langfang (Hebei), 2019): (a) - aerial view of the airport building; (b-d) - interiors airports complex structure (Source: http://www.zahahadid.com (13.07.2020))
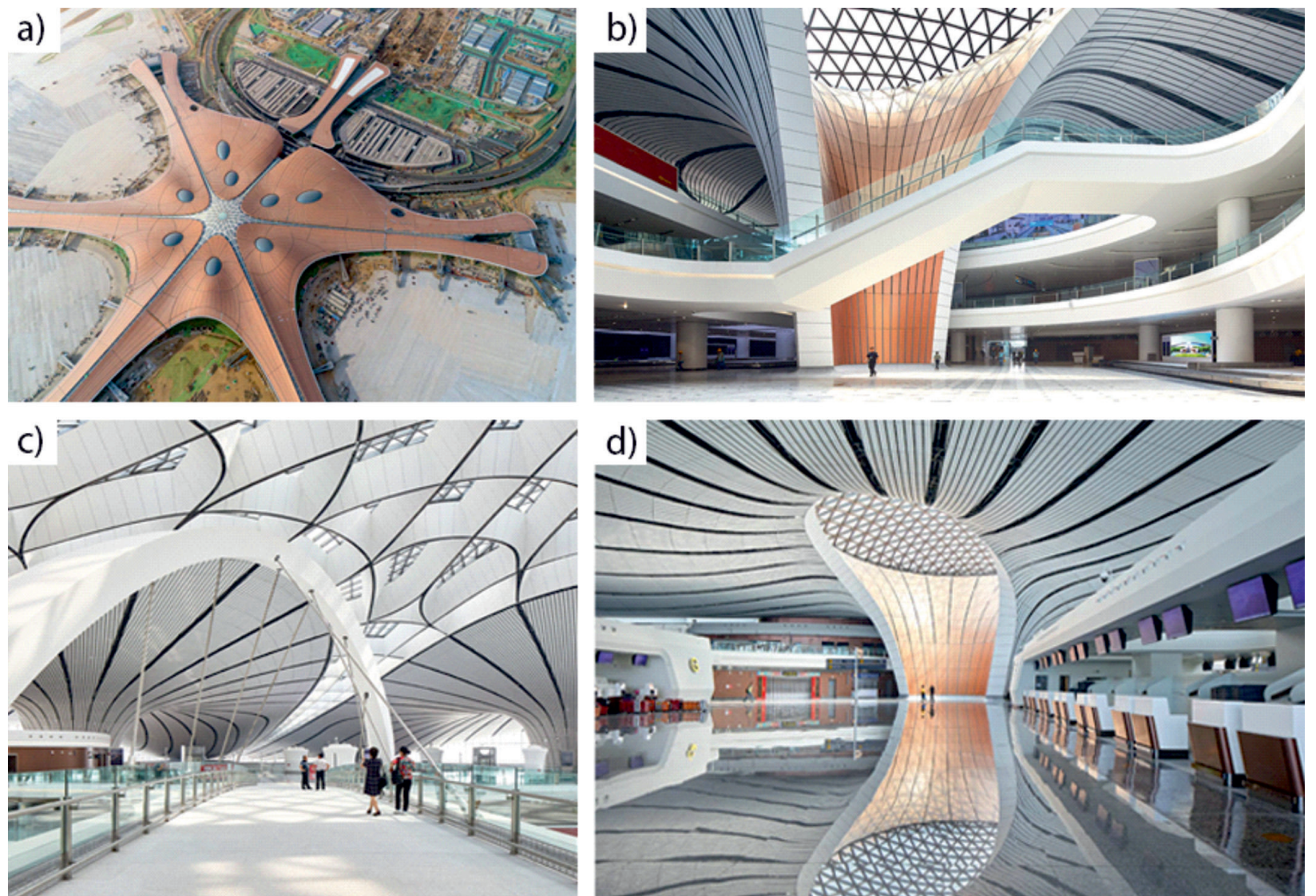

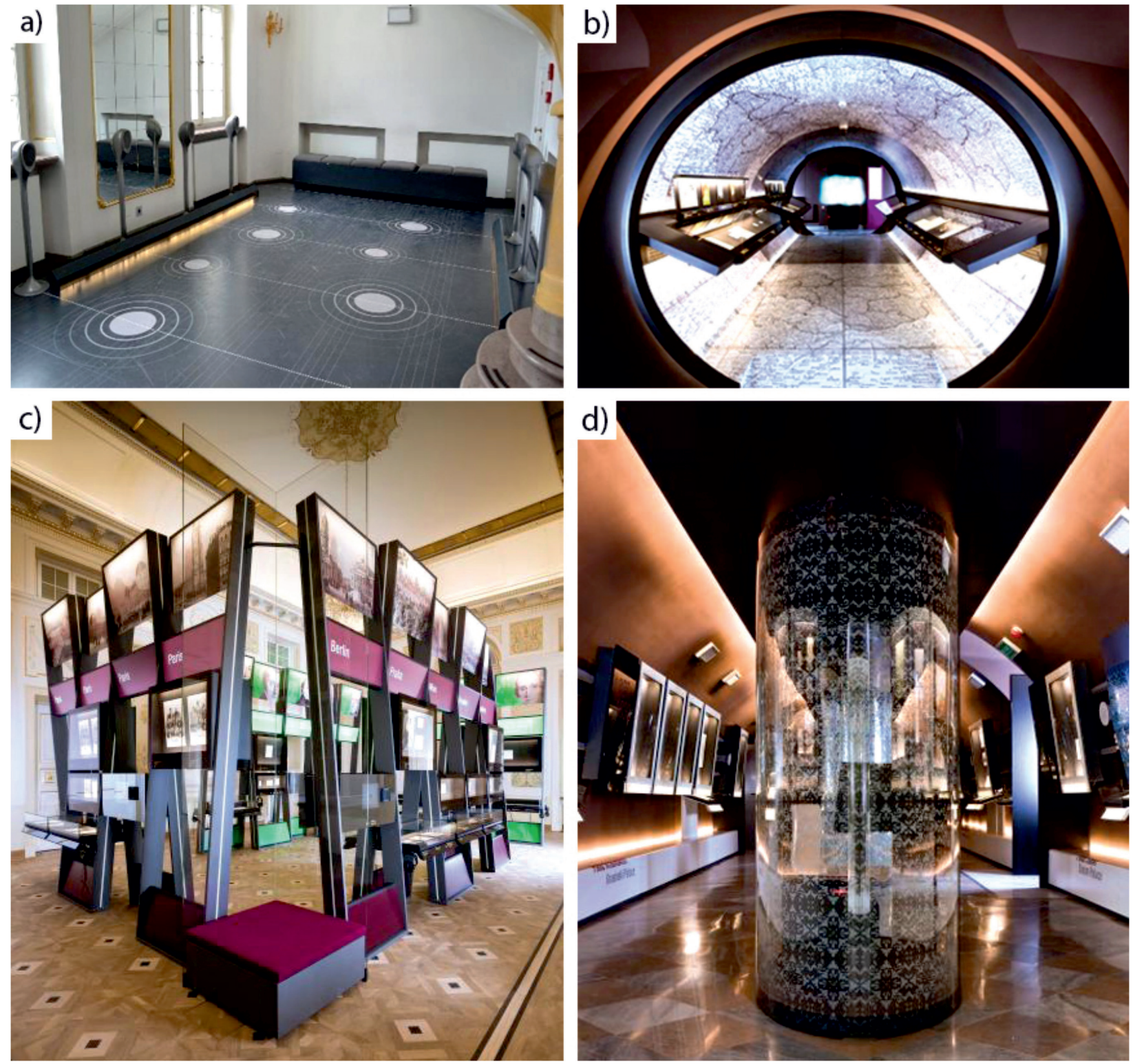

III. 2. F. Chopin multimedia museum (Italian arch. studio «Migliore + Servetto», Warsaw, 2010): (a) - interiors of the "Music Salon»; (b-d) - audioroom interiors (Author photo: Svitlana Kysil)

made specifically for the exhibition. This is a modern multimedia interactive museum complex that expresses media technologies and visual art.

An example of the implementation of system-structural principles in residential interiors is the modern solutions for economy-class apartments. For example, a studio apartment of $30 \mathrm{~m}^{2}$ in St. Petersburg (Fig. 4). The specifics of their planning are that they actually consist of two rooms: a shared bathroom (sitting bath or shower) and a living room, which focuses on several main functional areas for: sleeping, cooking, eating, resting, meeting visitors, storing things. In a small area home interior design, the importantmost is that it should not be seen as overloaded with decorative elements. It is preferable to give functional minimalism, restrained modernity or traditional Japanese style, etc. (Kysil SS, 2018, http://nbuv. gov.ua/UJRN/artges_2018_1_8).
The performed analysis of factors, with the further development of the principles of formation of the modern interiors design, was able to identify and formulate a general method for designing the interior spaces.

\section{Methodology of the design of modern interiors}

When designing modern interiors, the following features should be comprehensively and consistently addressed: urban location; functional zoning with efficient use of areas according to their purpose; rational architectural planning and compositional solution; object-spatial content; the use of advanced technological equipment and advanced engineering systems; fire prevention, etc. Creating a contemporary interior design should be based on systemic, environmental and innovative approaches. Modern 

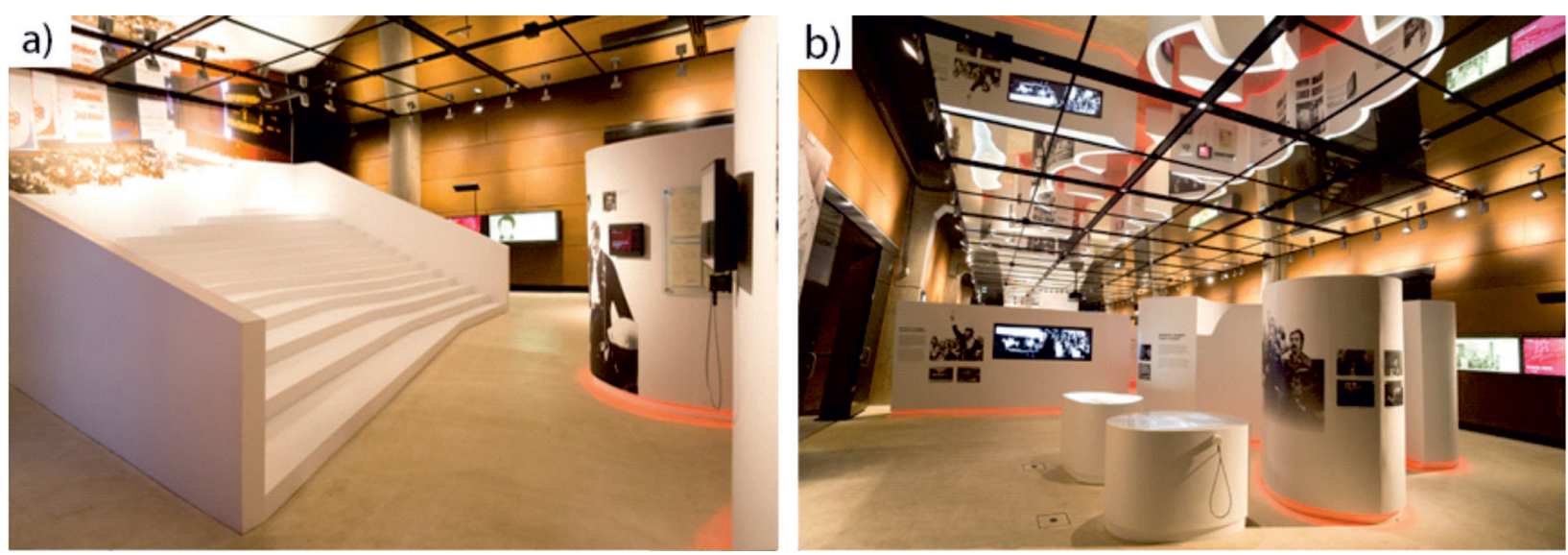

III 3. European Solidarity Center in Gdansk. Exposition halls interiors (arch. «Fort Architects», Gdansk, 2015): (a, b) - permanent exhibition (Author: Svitlana Kysil)

interior design that is developed on this basis involves: considering the object of design at the global, regional and local levels; comprehensive and systematic analysis undertaken from different perspectives; the fullest consideration of the factors and conditions that influence its formation; study of the preconditions, limitations and possible environmental and other consequences of environmental intrusion.

Therefore, the methodology of the design of modern interiors should include: identifying a number of interacting parameters, which as a whole will affect the choice of design and technical means; analysis and consideration of objective conditions of the formation of the interior space; translating the design into a material that is appropriate to the nature of the interior space.
Modern interior design that is based on a systematic approach means that every element of the system or subsystem should be considered as a holistic system at a certain level. In turn, each component of the interior space is treated as an element of a holistic system. Using the systematic approach as a bsis, the integrity and unity of modern interiors determines the only criterion of optimality to which various indicators are subordinated. In a systematic approach, the essence of which is to fulfill the requirements of the general theory of systems, the object of design-a modern interior space, is considered a set of interdependent elements and components that make up a system that joins their components using a common purpose.

III. 4. Studio apartment of $30 \mathrm{~m}^{2}$ (designer A. Timonin, St. Petersburg, 2018): (a-c) - interiors of the rooms (Source: https://www.pufikhomes. com/en/tag/rossiya/ (13.07.2020))
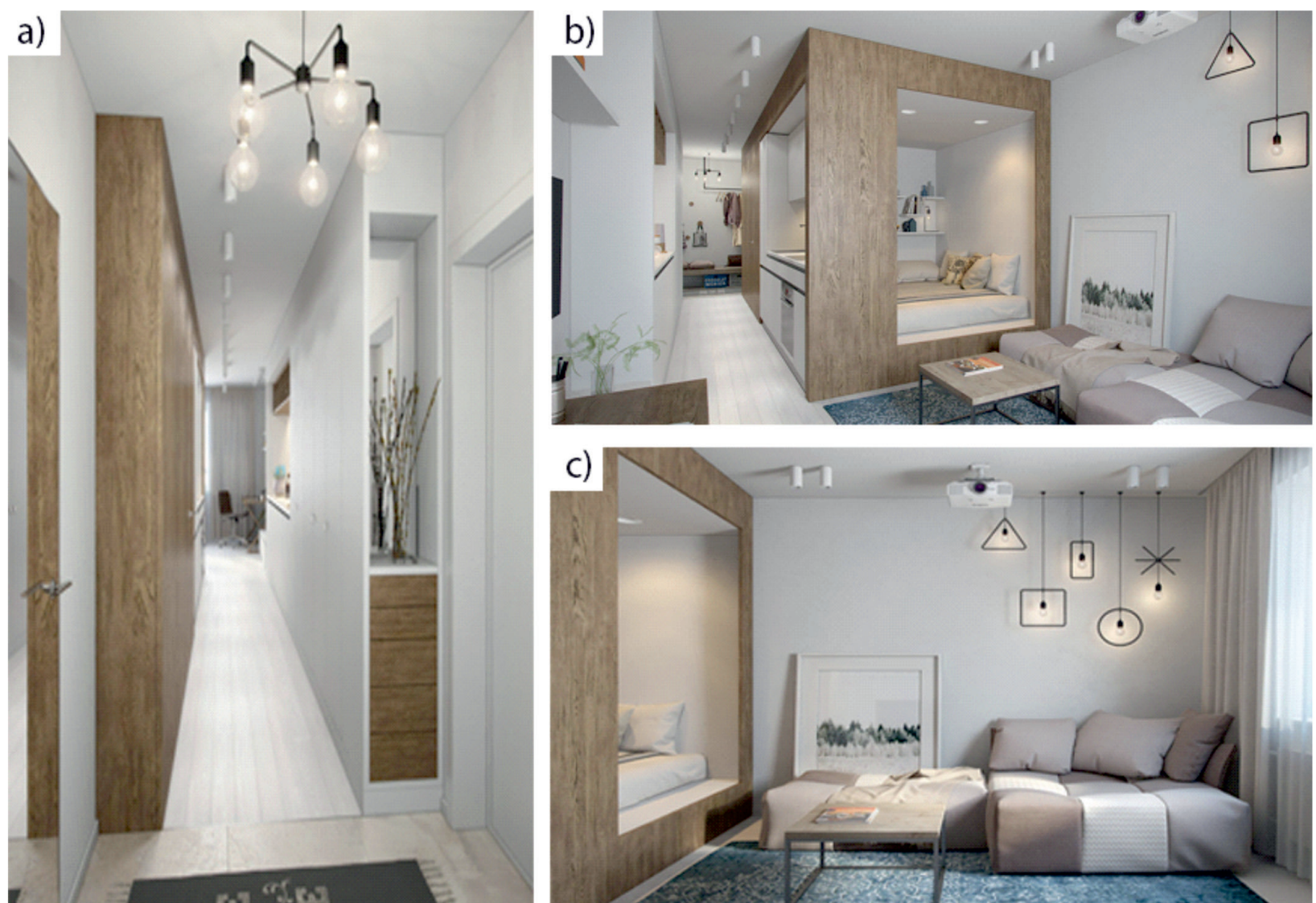
Therefore, when preparing a modern interior design, it is necessary to define appropriate hierarchical system-structural levels of the organisation of its architectural environment.

The first hierarchical level of a design is the design of the entire interior environment of the building, connected by a single integrated space. At this level, the overall spatial and design concept and ideology of the whole interior space is formulated, as are the conditions of its interconnection and interaction with the open space of the environment. The design of a modern interior should be combined with a holistic conceptual design and a common compositional design.

The second hierarchical level is the arrangement of the interior design of specific rooms, taking into account other open and closed elements of the environment. At this level, as in the previous one, the following elements are defined: functional zoning, architectural and spatial composition, general colour solutions-not of the general interior space of the building, but individual functional components and premises. When designing a modern interior, particular attention should be paid to the colour design, to lighting and to the selection of lighting equipment. The proper selection of colours in conjunction with lighting equipment can visually increase or decrease the apparent size of the room, create a comfortable, unique atmosphere for visitors and an emotional effect.

The third structural block is the subjective filling of the interior and the compositional, artistic and figurative design of the main system-forming elements, fragments of the particular room interior in the context of its general environmental design. The elements of object content of the interior, first of all, include its furniture and equipment that has a functional purpose. Namely: furniture, accessories, visual advertising, infographics, equipment, small architectural forms, elements of engineering infrastructure, etc. The artistic design of the equipment, along with the need to comprehensively address specific functional, structural, ergonomic, economic and environmental conditions of environmental formation, should meet aesthetic requirements that will reflect a certain style of the environment. Indeed, the design of furniture, flower beds, fountains, sculptural installations, lamps, etc. should be formulated in accordance with the general conceptual design of the interior.

The saturation of the composition, the creation of stylistic expressiveness of the modern interior is also due to the expressive details of the decor and the synthesis of the arts. Therefore, the fourth hierarchical level will be comprised of the aesthetic solution of the decor details and the arts synthesis if necessary,. The harmonious synthesis of design objects with fine arts and crafts (artistic ceramics, monumental and decorative painting, artistic textiles, sculptural compositions, wood, metal, glass, etc.) is a significant means of their organic interaction and connection with the interior. Here one should also keep in mind the skillful use of landscaping and phytodesign-since plants, herbs, flowers and their meaningful and aesthetic combinations are of great importance in interior design.
Finally, the last fifth leve/ in the interior design process is the use of appropriate building materials and products. The skillful use of traditional building materials-wood, stone, ceramics, etc., and their texture gives special natural artistic and figurative features and saturates the space with uniqueness. At the same time, the high development of scientific and technological progress and the introduction of nanotechnology further opens up wide aesthetic and artistic forms of application along with traditional innovative products and materials (concrete, reinforced concrete, anodised metal, glass and other mineral materials and products, polymeric materials, etc.) to create extraordinary environmental compositions and to realise bold creative design ideas. It is worth to expand the above statement with the fact that the design of an interior should be periodically updated, upgraded, and its decoration changed-it should not be static. At the same time, it is important to ensure the stylistic integrity of the spatial and artistic-figurative solution of the interior space of civil buildings.

Each element of the system or subsystem of a modern interior should be considered as a coherent system of a certain level, which links their components to a common purpose. Thus, the hierarchical levels of organisation of the architectural environment in shaping the design of interiors of civil buildings are as follows:

- organisation of the entire interior environment of the building or complex of buildings, which unites said complex;

- organisation of the internal environment of specific premises of a building or complex;

- substantive filling of the environment;

- synthesis of arts;

- the use of appropriate building materials and products.

These system-structural principles of the interior space typology will allow designers to achieve a more in-depth understanding of this phenomenon and to reliably define the requirements and conditions of their formation and realisation at different hierarchical levels.

Conclusions. The article explores the peculiarities of twenty-first century interior design. With the changes of socio-economic factors, with the development of technologies, new capabilities for shaping the design of modern interiors emerge. An analysis of global experience in the formation of contemporary interior design of different typologies shows the development of new approaches to the creation of highly efficient innovative spaces: multifunctional, comfortable, accessible, environmental, aesthetic, etc. The creation of a modern interior requires the integration of all functional and spatial elements into a single interconnected organism to ensure sustainability and efficiency, with embedded energy efficiency and eco-design strategies. 
The basic external (socio-economic, natural-climatic, city-planning, ecological and material-technical) and internal (typological, ergonomic, psycho-emotional, technological and cultural) factors of the modern interiors design formation were reviewed, and various modern tendencies of their changes were analysed, so as to formulate general hierarchical system-structural principles of their design: socio-economic relevance, expediency, multivariance, dynamism and aesthetic harmonisation.

A methodology (sequence technique) of designing modern interiors has been formulated, according to which the issues of their rational functional, spatial, structural, technological and engineering organisation should be designed. Each element of a system or subsystem of interior spaces must be considered as a coherent system of a certain level, which connects their components for a common purpose. The hierarchical levels of organisation of the architectural environment in the formation of interior design are the following: the organisation of the entire interior environment of the building or complex of buildings that unite said complex; the interior design of specific premises of a building or complex; the substantive content of the environment; the synthesis of arts; the use of appropriate construction materials and products.

Such system-structural principles of modern interior design will allow to a more in-depth understanding of this phenomenon, to accurately define the requirements and conditions of their formation and realisation at different hierarchical levels and can be used effectively for further studies.

\section{REFERENCES}

[1] ISO 13407. Human-centred design processes for interactive systems, Geneva: International Standard Organization, 1999.

[2] Cohen J L (2004) Le Corbusier, Köln: Taschen Verlag.

[3] Sloan Julie L (2001) Light Screens: The Leaded Glass of Frank Lloyd Wright, New York, Rizzoli International Publications.

[4] Krohn C (2019) Walter Gropius. Buildings and Projects, Berlin, Basel: Birkhäuser.

[5] Abyzov V (2017) Modern Conditions and the Impacts of the Creation of Architectural Environment. Proceedings of the World Multidisciplinary Civil Engineering-Architecture-Urban Planning Symposium - WMCAUS, Materials Science \& Engineering - IOP (Volume 245), (Czech Republic, Prague, June 12-16, 2017), Bristol, Published online: November 4, 2017. Available at: https://iopscience.iop.org/ article/10.1088/1757-899X/471/8/082004/meta (13.07.2020)

[6] Poliakova OV (2018) Artistic-figurative design basics of an intelligently managed housing environment (PhD Thesis), Kyiv: Kyiv National University of Technologies and Design.

[7] Rozhdestvenskaia ES (2007) Principles of incorporating an architectural object into the environment (by the example of contact zones of cities) (PhD Thesis), Nizhny Novgorod: Nizhny Novgorod State University of Architecture and Civil Engineering.

[8] Smoliar YM, Mykulyna EM, Blahovydova NH (2010) Ecological basis of architectural design. Moscow: Akademyia.

[9] Voskresenskyi YN (2004) Harmony and ecology: ways of integration. Landshaftnaia arkhytektura. Dyzain no. 3 pp. 66-74.

[10] Abyzov V A (2009) Theory of Architecture-\&-Construction Systems Development. Monograph, Kyiv: KNUKiM.

[11] Alkhalidi AS (2014). Future Directions in Interior Design Education. ICIRS Conferences, Journal of Leadership and International Development.

[12] Brown T, Wyatt J (Winter 2010) Design Thinking for Social Innovation, Stanford Social Innovation Review Vol. 8, no. 1, pp.30-35. Available at: https://ssir.org/articles/entry/design_thinking_for_social_innovation

[13] Buchanan R (1992) Wicked Problems in Design Thinking, Design Issues, no. 8(2), pp.11-21.

[14] Hughes P (2010) Exhibition design, London: Laurence King.

[15] Kysil SS (2018) Tendenciyi formuvannya inter'yeriv suchasny ' $x$ ekonomichny 'x kvarty' $r$ z minimal 'noyu ploshheyu [Interior formation trends of modern economic apartments with minimum square]. Art and Design (electronic journal), (no. 1), pp.67-74. Available at: http://nbuv.gov.ua/UJRN/artges_2018_1_8 